\title{
Postharvest Adaptation Strategies to the Effects of Temperature Variations and Farmer-Miller Practices on the Physical Quality of Rice in Cameroon
}

\author{
Sali Atanga Ndindeng1,2, Delphine Lamare Mapiemfu², Wilson Fantong3, \\ Valentine P. Nchinda ${ }^{2}$, Zachée Ambang ${ }^{4}$, John T. Manful ${ }^{1}$ \\ ${ }^{1}$ Grain Quality and Postharvest Unit, Africa Rice Center, Cotonou, Benin \\ ${ }^{2}$ Food Science and Technology Laboratory, Institute of Agricultural Research for Development (IRAD), \\ Yaoundé, Cameroon \\ ${ }^{3}$ Centre for Hydrological Research, Institute of Mining \& Geological Research (IRGM), Yaoundé, Cameroon \\ ${ }^{4}$ Department of Plant Biology, University of Yaoundé-I, Yaoundé, Cameroon \\ Email: $\underline{\text { S.Ndindeng@cgiar.org }}$
}

Received 2 October 2013; revised 28 October 2013; accepted 25 November 2013

Copyright (C) 2014 by authors and Scientific Research Publishing Inc.

This work is licensed under the Creative Commons Attribution International License (CC BY).

http://creativecommons.org/licenses/by/4.0/

(c) (i) Open Access

\section{Abstract}

In order to develop simple and adaptable measures to reduce the impact of changing climatic conditions and poor postharvest practices on grain quality, data on temperature and postharvest practices were collected and correlated with physical grain quality parameters for 3 rice development hubs (Ndop, Lagdo and Mbam) in Cameroon. Inter-annual variations in temperature and thermal amplitudes were the highest in Ndop followed by Mbam and the least in Lagdo. When the same rice variety was grown in the hubs and milled with a laboratory hand dehusker, the mean chalky score was highest in Ndop (18\%) and least in Mbam (11\%). In addition, Ndop recorded higher grain fissures and broken fractions compared to Mbam or Lagdo. Positive correlations were observed between thermal amplitudes, grain fissures and the proportion of broken fractions. However, rice milled using commercial mills located in the hubs recorded the highest broken fractions in Mbam (54\% - 63\%), followed by Lagdo (43\% - 52\%) and the least in Ndop (35\% - 38\%). The type of mills in the hubs was responsible for these differences as Mbam had only Engelberg types mills that recorded higher broken fractions than in Ndop where only rubber roll mills were present $(P<0.05)$. Lagdo had a mixture of Engelberg and rubber roll mills and recorded intermediate broken fractions. Proper parboiling, recovery and processing of poorly filled and immature grains during parboiling and processing of low-grade and fine broken rice into product generally accepted by the local population were demonstrated as simple adaptation strategies to mitigate 
the adverse effects of changing climatic conditions and poor postharvest practices on the physical quality of rice especially in sub-Saharan African countries.

\title{
Keywords
}

\author{
Postharvest Loss, Thermal Amplitude, Temperature Variations, Climate Change, Practices, Grain \\ Quality
}

\section{Introduction}

Rice (Oryza. sativa L.) and to some extend (Oryza. glaberrima S.) is fast becoming a global staple and its demand is on the rise especially in sub Saharan African (SSA) countries. Rice production per hectare has to rise above $12 \%$ annually to keep pace with the expected demand. In addition, rice postharvest operations will have to be tailored in such a way as to reduce losses and add value to the crop. This cannot be achieved without taking into considerations the effect of changing climatic conditions on rice production. Climatic factors that affect rice production and quality include heat (temperature and humidity), carbon dioxide levels, drought, salinity and flooding. Several authors have reported on the effects of changing climatic conditions on rice production and strategies for adaptation [1]-[3]. A detailed review on how changing climatic conditions affect rice production with emphasis on the physiological and agronomic basis for possible adaptation strategies has been carried out [3]. It is worth nothing that the progress made on how to increase rice production in the face of changing climatic conditions has been in the areas of germplasm improvement and crop management. Little has been reported on post-production adaptation strategies although this area is of utmost importance especially in SSA countries where harvesting and postharvest practices are still very rudimentary. High temperature affects cellular and developmental processes leading to reduced fertility and grain quality [4]. Decreased grain weight, reduced grain filling, higher percentage of white chalky rice and milky white rice are common effects of high temperature exposure during the ripening stage in rice [5]-[7]. Poor threshing, drying and milling methods may also cause fissures thus leading to high broken fractions. Low physical quality of the rice grain adversely affects the market price of rice leading to a reduction in the income of value-chain operatives.

Rice parboiling, if properly carried out can be an effective way of eliminating chalkiness in milled rice grains. In addition, adding value to low-grade broken rice by processing into other products like biscuits may also be an effective strategy of reducing the adverse effects of high temperatures and poor postharvest operations on the physical quality of the rice grain. Parboiled rice is rice that has its starch partially gelatinized by soaking paddy rice or brown rice in water followed by steaming and a drying process [8]. A major reason for parboiling rice in SSA is to reduce grain breakage during milling although it has also been shown that the water soluble minerals and vitamins content of parboiled rice are higher than that of non-parboiled rice [9]-[11]. Parboiling increases grain translucency and decreases chalkiness due to starch gelatinization. It also increases grain hardness and manages to reduce grain breakage as a result of the swelling of the starchy endosperm during gelatinization, which heals the pre-existing defects [12]. In Cameroon, rice parboiling is done mainly in the Northwest and Western regions. However, traditional parboiling does not consistently lead to superior rice quality because processors often have limited knowledge on the basic technicalities of parboiling, despite its simplicity [13]. Traditionally, paddy rice is often pre-cooked with excess water, which can have deleterious effects in terms of quality [14]. In this study, the level of chalky rice, fissures in rice grains and broken rice fractions in three contrasting "rice development hubs" in Cameroon are evaluated. The main factors responsible for reduced grain quality in each hub are identified. It was confirmed that the use of an improved parboiling technique and processing of rice with a high proportion of broken fractions into biscuits or other products generally accepted by the local population can be implemented as adaptation strategies to the effects of high temperatures and poor postharvest operations that result in poor quality milled rice in SSA countries.

\section{Materials and Methods}

\subsection{Description of Rice Sample Collection Sites}

Rice samples were collected from three "rice development hubs" (RDHs) in Cameroon [15] namely Ndop, 
Lagdo and Mbam. RDHs are zones (rice ecologies) where rice research outputs will be integrated across the rice value-chain to achieve the desired development outcomes and impact [16]. Rice samples were also collected from an experimental station managed by the Japan International Cooperation Agency (JICA) at Nkolbisson where Good Agricultural Practices (GAPs) are observed. Nkolbisson is a peri-urban community located in the Mbam RDH. The samples from the experimental station were used as checks since their quality was expected to be high. In Lagdo, Engelberg mills (which have single compartment for dehusking and polishing) and rubber roll type mills (which have a separate dehusking and polishing compartment) are present [17]. In Mbam, only Engelberg mills are present while in Ndop, only the rubber roll type mills are present. In all the hubs, only manual threshing was practiced either by beating rice panicles on steel drums, pieces of wood or stones to release the paddy grains. Traditional parboiling, which does not consistently result in good quality parboiled rice, is popular in Ndop RDH but not in the other hubs.

\subsection{Collection of Data on Temperature}

Data on temperature variations for the last six decades (1955-2002) for the 3 RDHs were collected from the Centre for Hydrological Research, Institute of Mining and Geological Research, Yaoundé-Cameroon. Data on temperature amplitudes for the $3 \mathrm{RDHs}$ were also collected.

\subsection{Rice Varieties and Moisture Determination}

Samples of the major rice varieties grown in each RDH were collected. These samples (paddy and white milled rice) were collected from farmers and millers. For each farmer, the method used to thresh the rice was recorded. Milled samples were collected from millers at the mill houses. The type of mills used to mill the rice was also recorded. The moisture content of the grains was determined using a Satake Rice Moisture meter (Satake Co. Ltd., Tokyo, Japan) according to manufacturer's instructions and expressed as a percentage. All determinations were carried out in triplicates.

\subsection{Milling of Rice Samples}

Rice samples were milled using three different mills; the Engelberg type mill (GFAMO-CIG, Garoua, Cameroon), the Satake commercial rubber roll mill (Satake Co. Ltd., Tokyo, Japan) and the Satake Laboratory hand de-husker (Satake Co. Ltd., Tokyo, Japan).

\subsection{Determination of Percent (\%) Chalky Grains}

When part of the milled rice kernel was opaque (white spot) rather than translucent, it was considered "chalky". Two hundred (200) milled rice grains were placed on a blue cardboard background to visually identify under white light the grains that had white belly, white centre, white back or a combination of these [18]. The percent chalky grains were determined as shown below: $\%$ Chalky grain $=$ number of chalky grain $\times 100 / 200$.

\subsection{Determination of Fissures in Grains}

Fifty (50) grains of paddy or milled rice were randomly selected from each sample and viewed under HP Photosmart C8100 scanner (Hewlett Packard, Japan). The flatbed million-color option was used to acquire a 600 dpi TIFF format image on a black background. The number of fissures in grains was determined using the image analysis method of [19] with the following modifications:

The images were acquired on a dark background; the software, ImageJ64 was run on a Mac OS X Version 10.6.8 platform, with a $2.4 \mathrm{GHz}$ Intel Core i5 Processor; and analysis of particles options were; size = 200-infinity, circularity $=0-1$ and show $=$ overlay outline.

The total number of fissures observed in 50 grains was reported.

\subsection{Determination of Broken Fractions}

The level of broken rice fraction was determined using a sample of $20 \mathrm{~g}$ of milled rice. The broken grains were manually selected from the whole grains and weighed and the results expressed as percentage of broken fraction 
in milled rice.

\subsection{Rice Parboiling}

Rice was parboiled using two procedures: 1) A uniform steam-distributed (USD) parboiling technology [20], which produces rice that mimics high-grade imported rice in physical and eating characteristics [21]; 2) A traditional technology that does not consistently lead to high quality parboiled rice [22]. After parboiling, the samples were milled and the following quality parameters were recorded: percentage broken fraction, number of fissures in 50 grains and percent chalky grains.

\subsection{Estimation of Poorly Filled and Immature Grains and Their Recovery}

Fifty (50) kilograms of paddy rice was completely submerged in 100 liters of water. The grains that floated were recovered and weighed rather than discarding as commonly practiced by local processors. The poorly filled grains collected during the washing of paddy rice for parboiling were separately parboiled, dried, milled, weighed and the weight of milled grains expressed as a percentage of milled parboiled rice obtained from completely filled grains.

\subsection{Production of Rice Biscuits from Low-Grade Broken Rice Fractions and Their Acceptability}

Completely broken (100\%) rice fraction that has been previously shown to have a very low market value [21], [23] was cleaned and ground in to flour using a regular corn mill. The flour was sieved and the fine fraction (particle size less than $0.49 \mathrm{~mm}^{3}$ ) and used to produce biscuits according to previously described methods [24] with slight modifications. Wheat biscuits were also produced and used as control samples. With the aid of a questionnaire, a trained sensory panel consisting of 12 persons was also asked to score the color, taste and texture of the biscuits produced on a hedonic scale (like, dislike and not sure). The panelists were not informed about the constituent of the product being tested and all samples were tested in duplicates.

\subsection{Statistical Analysis}

The data obtained were analyzed using the Statistical Package for Social Sciences (SPSS version 10.1.4 (2002)) at a $5 \%$ significance level. For each variable, mean \pm 2 Standard Error (SErr) were computed for each RDH and the results plotted on a chart. Data on the physical quality attributes of rice from the different RDHs or processed using different procedures were compared by one-way ANOVA to determine variations in the means. Pearson correlation was used to determine the relationship between thermal amplitude; number of fissures in grains and percentage broken fractions in rice milled using the Satake Laboratory hand de-husker (Satake Co. Ltd., Tokyo, Japan). Using the least significant difference (LSD), varietal classes for chalkiness, fissures and broken fractions were created for the most popular rice varieties grown in Cameroon.

\section{Results and Discussions}

\subsection{Major Rice Varieties Cultivated in Cameroon}

A total of 13 rice varieties were collected with at least 3 varieties selected per RDH. Table 1 shows the characteristics of each RDH in terms of threshing method, types of mills present and major rice varieties cultivated. IR46 is an improved variety from the International Rice Research Institute (IRRI), The New Rice for Africa (NERICA)-NERICA-3 and -8 are improved rice varieties from Africa Rice Center (AfricaRice) suitable for upland ecologies. NERICA-L42 is also from AfricaRice but suitable for lowland or irrigated ecologies. TOX-3145, M-13, CICA-8 and ITA-300 are all improved rice varieties from AfricaRice suitable for irrigated ecologies. "Tianan-5" is an improved rice variety from Thailand suitable for lowland ecologies vulgarized in Cameroon by the Upper Noun Valley Development Authority (UNVDA). "Bakala" and "Madam" are local rice varieties that have not yet been characterized but widely cultivated by farmers in Tonga area located in the Mbam hub because they believe these varieties provide some health benefits (personal communications). NERICA-3 was cultivated in all RDHs indicating that farmers in all the RDHs in Cameroon have adopted this variety and that it is suitable for upland ecologies in all hubs in the country. 
Table 1. Characterization of rice production site in Cameroon with respect to threshing method, types of mills and major rice varieties cultivated.

\begin{tabular}{|c|c|c|c|}
\hline Site & Threshing method & Type of mills & Rice varieties collected \\
\hline Lagdo hub & Beating on a steel drum & $\begin{array}{c}\text { Satake commercial rubber rolls and } \\
\text { Engelberg }\end{array}$ & $\begin{array}{c}\text { IR-46 } \\
\text { NERICA-3 } \\
\text { ITA-300 }\end{array}$ \\
\hline Mbam hub & Beating on a steel drum & Engelberg only & $\begin{array}{c}\text { Madam } \\
\text { Bakala } \\
\text { M-13 } \\
\text { CICA-8 } \\
\text { NERICA-3 }\end{array}$ \\
\hline Ndop hub & Beating on a piece of wood & Satake commercial rubber rolls only & $\begin{array}{c}\text { Tainan-5 } \\
\text { TOX-3145 } \\
\text { NERICA-3 }\end{array}$ \\
\hline $\begin{array}{l}\text { JICA }^{*} \text { experiment farm } \\
\text { Yaoundé }\end{array}$ & $\begin{array}{c}\text { Threshing machine and beating on } \\
\text { a piece of wood }\end{array}$ & Satake laboratory rubber roll only & $\begin{array}{c}\text { NERICA-L42 } \\
\text { NERICA-8 } \\
\text { NERICA-3 }\end{array}$ \\
\hline
\end{tabular}

*Japan International Cooperation Agency.

\subsection{Temperature Variations in Different RDHs of Cameroon}

Between 1955 and 1990, variations in mean annual temperature showed a similar pattern in the three RDHs with inter-annual variations not exceeding $\pm 1^{\circ} \mathrm{C}$ except in the following years in Lagdo hub (1972, 1985, 1986, 1987 and 1990), Ndop hub (1987), and Mbam hub (1987, 1988 and 1990). Between 1990 and 2002, Lagdo hub had inter-annual variations $>1{ }^{\circ} \mathrm{C}$ only in three years $(1990,1998$ and 2002) while in Ndop and Mbam hubs, this happened respectively in 9 years (1993, 1994, 1995, 1996, 1997, 1998, 2000, 2001 and 2002) and in 5 years (1990, 1994, 1995, 1998 and 2002). These results show that Ndop hub had the highest inter-annual variations in temperature between 1990 and 2002 followed by Mbam hub and least in Lagdo hub (Figure 1). Data on thermal amplitudes confirm highest variations in Ndop hub $\left(2^{\circ} \mathrm{C}-3^{\circ} \mathrm{C}\right)$, followed by Mbam hub $\left(0^{\circ} \mathrm{C}-0.5^{\circ} \mathrm{C}\right)$ and least in Lagdo hub $\left(<0^{\circ} \mathrm{C}\right)$ (Figure 2). The mean daily temperature in the month of August and September, which coincides with the ripening period of rice in Lagdo, Ndop and Mbam hubs were $27^{\circ} \mathrm{C}, 25.5^{\circ} \mathrm{C}$ and $23^{\circ} \mathrm{C}$ respectively. However, the difference between the daily maximum and daily minimum were largest in Ndop $\left(19^{\circ} \mathrm{C}\right)$ followed by Mbam $\left(16^{\circ} \mathrm{C}\right)$ and smallest in Lagdo $\left(15^{\circ} \mathrm{C}\right)$. Reference [25] reported that at the end of the 21st century, increases in surface air temperature will probably be around $1.4^{\circ} \mathrm{C}-5.8^{\circ} \mathrm{C}$, relative to the temperatures of 1980-1999 with increases in variability around the mean. Most of the rice in Cameroon is currently cultivated in regions where temperatures are above the optimal for growth (a maximum of 28 and a minimum of $22^{\circ} \mathrm{C}$ ). Any further increase in mean temperature or episodes of high temperatures during sensitive stages reduces rice yields and quality drastically.

\subsection{The Physical Quality of Rice from Three RDHs in Cameroon}

\subsubsection{Moisture Content}

There was variation in moisture content of rice samples from different RDHs in Cameroon (F-statistic $(F)=73.6$, Probability $(\mathrm{P})=0.0001$ ) using one-way analysis of variance (Figure 3 ). When P-value was less than 0.05 , the difference amongst the classes was significant; otherwise the difference was not significant. Samples from Lagdo hub had the lowest moisture content $(\leq 9 \%)$ in comparison with Mbam (12.5\%), Ndop (13.8\%) whereas samples from the JICA experimental station had moisture content of $14 \%$. Differences in moisture content may not necessarily be due to climatic condition but rather due to farmer's practices as samples from farmers and millers in Mbam hub have lower moisture content compared to that from JICA experimental station farm also located in the same hub. Over drying of harvested paddy or rice left too long in the field before harvesting may lead to very low moisture content values. This usually leads to fissures and a high proportion of broken fractions after milling. Paddy rice is best for milling or storage when moisture content is about $14 \%$ [26]. However, for longterm storage, moisture content of $12 \%$ is preferred given that the rice is kept dry and from insects [27]. 

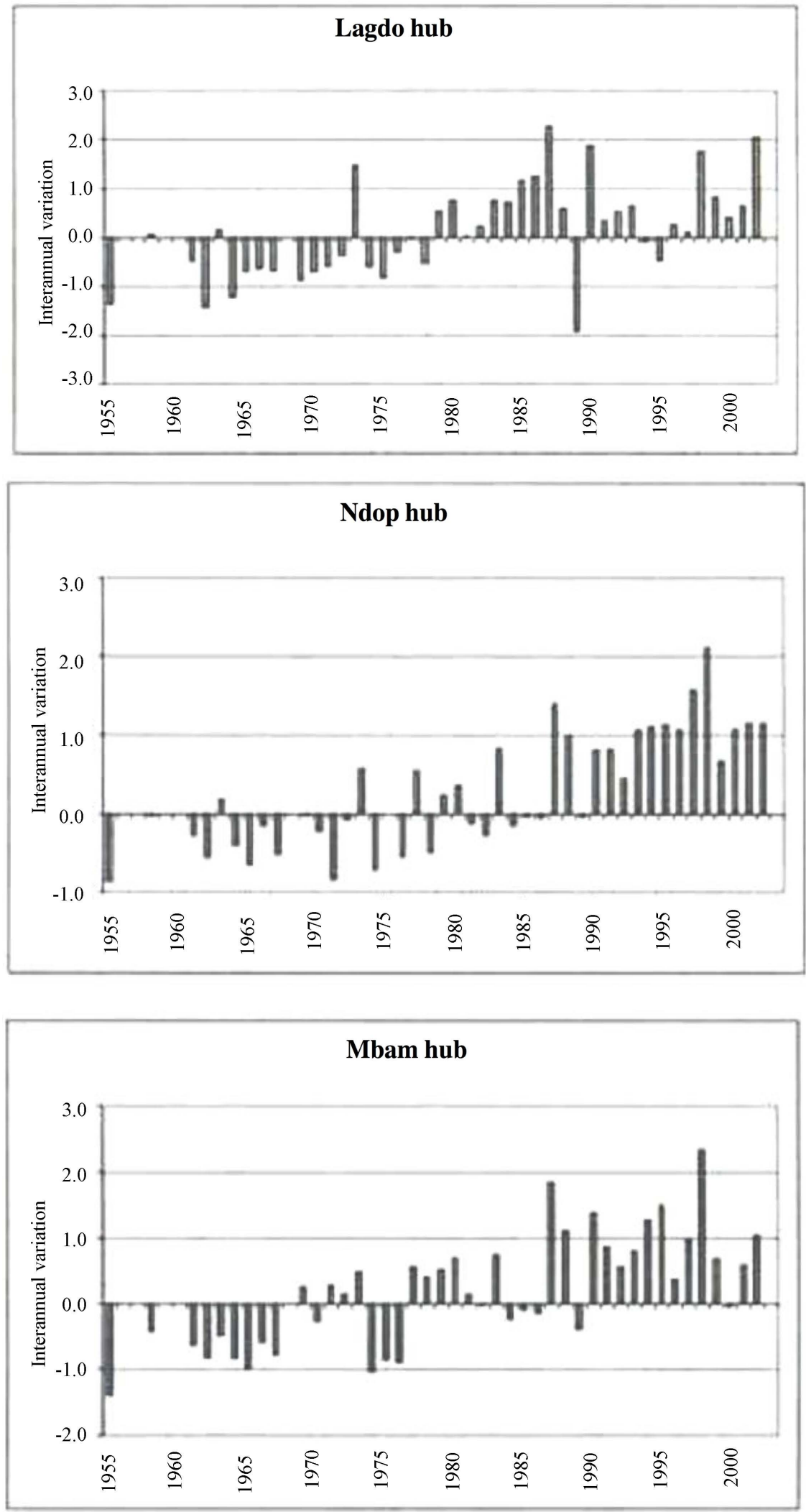

Figure 1. Inter-annual variation in temperature for three rice development hubs of Cameroon between 1955 and 2002. 


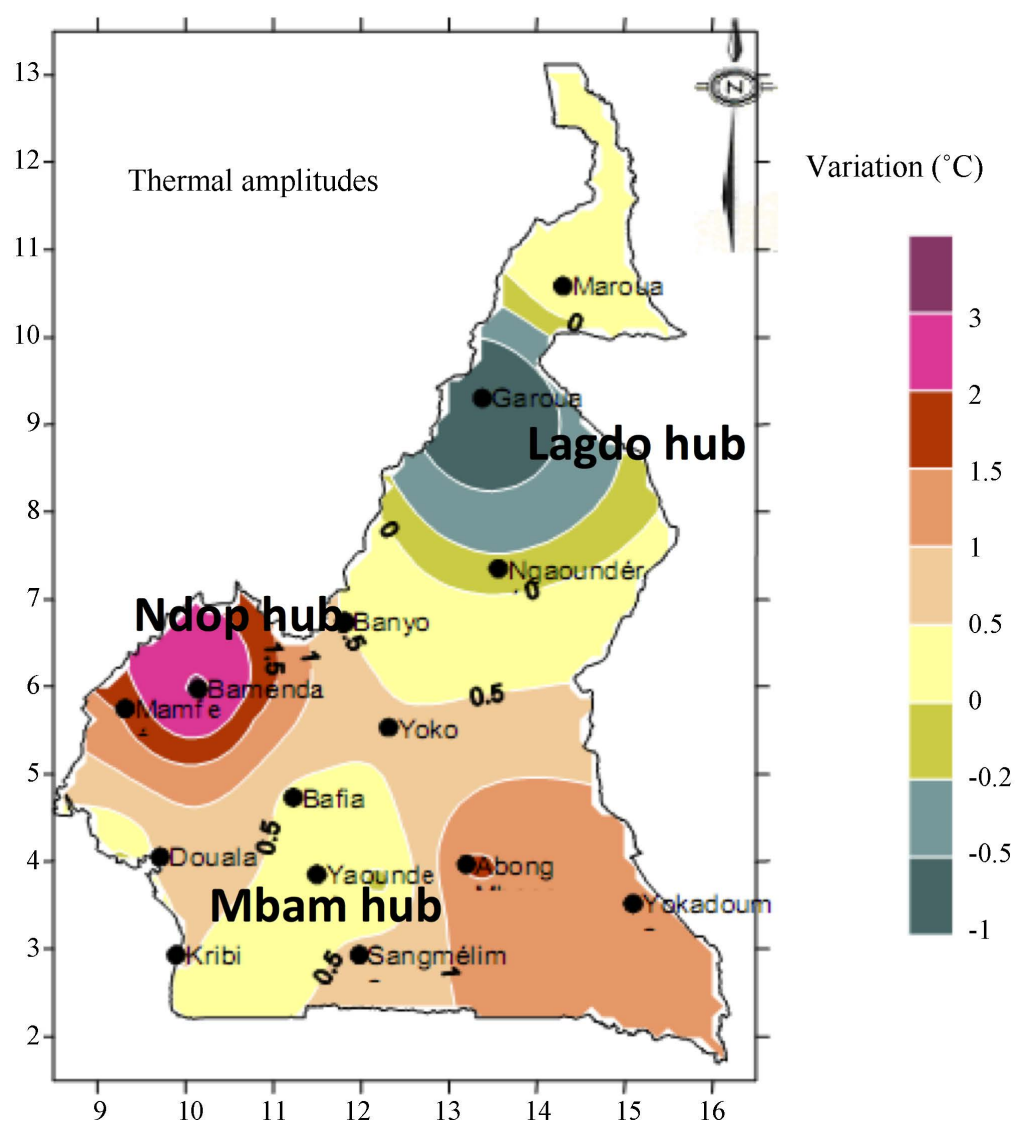

Figure 2. Thermal amplitudes for three rice development hubs of Cameroon.

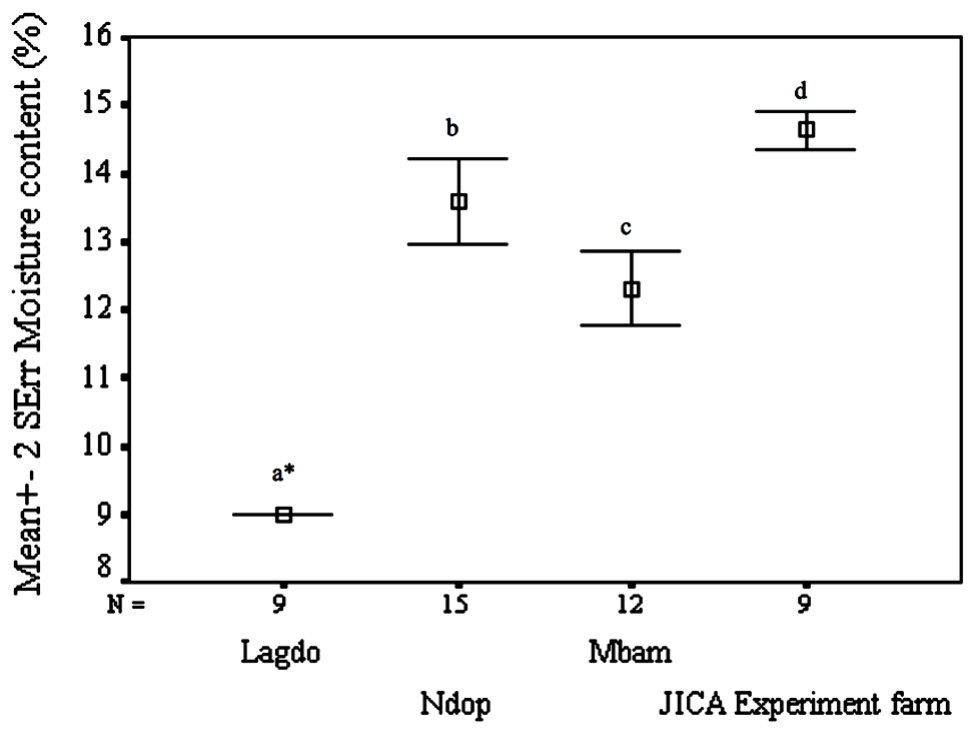

Rice Development Hub

Figure 3. Moisture content of paddy rice recorded in different rice development hubs in Cameroon and from the Japan International Cooperation Agency (JICA) rice project site in Nkolbisson, Yaounde-Cameroon. "Bars with different letters signify significant difference at 0.05 level. 


\subsubsection{Chalkiness Score}

The chalkiness score defined as the percentage of chalky grains in a rice sample was determined as described above. Rice varieties in this study were classified into three distinct chalky classes $(F=140.5, P=0.0001)$; highly chalky, moderately chalky and low chalky (Figure 4(a)). Two rice varieties_ITA-300 and Madam-had

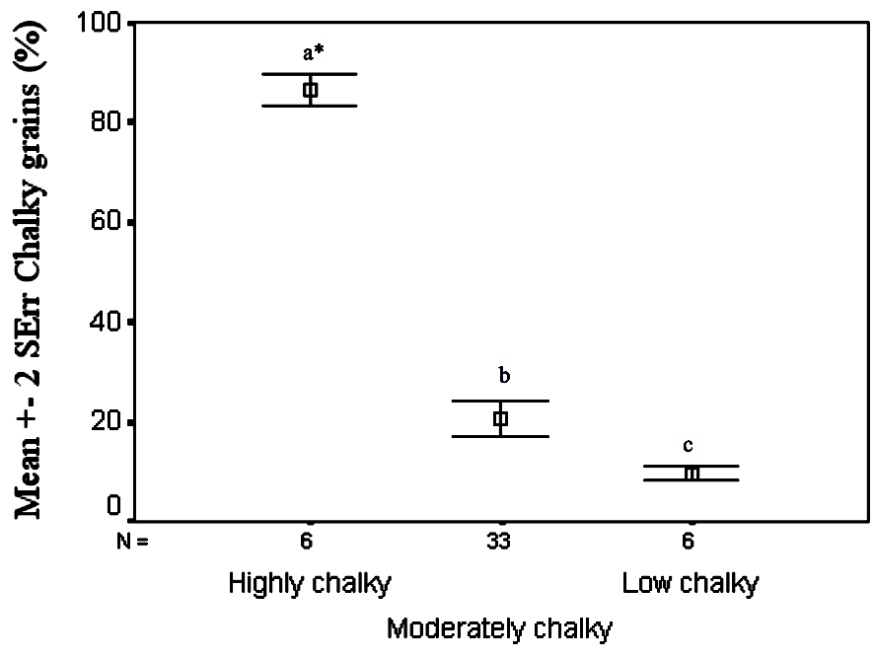

\begin{tabular}{lll} 
& \multicolumn{2}{l}{ Varietal Class chalkiness } \\
Highly Chalky & Moderately Chalky & Low chalky \\
- ITA300 & -IR46 & -NERICA-8 \\
- Madam & -NERICA-3 & \\
& - Tianan-5 & \\
& - Tox3145 \\
& -M13 \\
& -CICA-8 \\
& -NERICA-L42
\end{tabular}

(a)

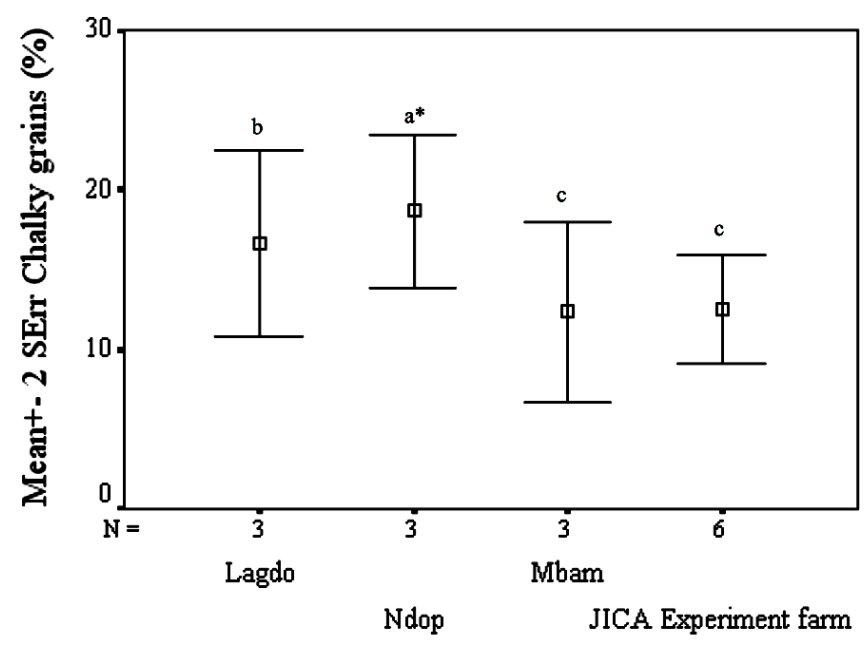

Rice Development Hub

(b)

Figure 4. (a) Classification of major rice varieties produced in Cameroon into three classes based on $\%$ chalky grains using a pooled sample from three rice development hubs (Ndop, Mbam and Lagdo) of Cameroon. *Bars with different letters signify significant difference at 0.05 level; (b) Rate of chalky rice recorded in different rice development hubs in Cameroon and from the Japan International Cooperation Agency (JICA) rice project site in Nkolbisson, Yaounde-Cameroon. *Bars with different letters signify significant difference at 0.05 level. 
high \% chalky score (82\% - 85\%), seven varieties-IR46, NERICA-3, Tainan-5, TOX3145, M-13, CICA-8 and NERICA-L42-had moderately chalky score (18\% - 25\%), and one variety-NERICA-8-had low chalky score ( $9 \%-12 \%)$. The mean \% chalky score from all RDHs in Cameroon was $>20 \%$ and could therefore be attributed the score of 9 [28]. We observed that the variety cultivated and neither the hub nor climatic conditions was important in explaining the differences in the chalkiness of the samples. In addition, no correlation was observed between thermal amplitude and chalkiness $(\mathrm{R}=0.30, \mathrm{P}=0.27)$. This was confirmed by the fact that varieties grown in the same hub under similar environmental conditions showed differences in chalky scores. However, when the same variety (NERICA-3) was grown in the three different hubs, the mean\% chalky scores were between 10\% - 20\% (Figure 4(b)) with the mean highest score (18\%) in Ndop hub and the least (11\%) in Mbamhub. These results suggested that environmental conditions in the Ndop hub may favor the development of chalkiness in rice varieties grown in that hub especially varieties predisposed genetically to be chalky. Chalkiness in rice, including white bellies and white cores [29] [30] is controlled genetically, but its extent can be affected by the environmental conditions experienced during the grain filling period [31]. Grain chalkiness is an undesirable quality criterion in the world market except for the production of special products, notably Japanese sake and risotto rice in Italy [32].

\subsubsection{Fissures in the Rice Grain}

Like chalkiness, the rice varieties were grouped into three distinct classes based on the number of fissures in 50 grains ( $\mathrm{F}=79.0, \mathrm{P}=0.0001$ ); highly fissured, moderately fissured and low fissured (Figure 5(a)). Two rice varieties-IR46 and Madam-were highly fissured (10 - 13 fissures in 50 grains), 5 varieties-ITA-300, NERICA-3, NERICA-8, CICA-8, NERICA-L42 - were moderately fissured (4 - 7 fissures in 50 grains) while 3 varietiesTainan-5, TOX-3145 and M13-were least fissured (1 - 2.5 fissures in 50 grains). A strong correlation ( $\mathrm{R}=0.87$, $\mathrm{P}<0.05)$ existed between fissures in paddy rice and the corresponding level of fissures in milled rice. Furthermore a strong correlation was observed between thermal amplitudes and fissures in rice. Although different rice varieties showed variations in fissures, NERICA-3 that was grown in all hubs and showed a moderate level of fissures throughout was selected to study the hub effect. Fissures in rice grains were high in Ndop hub (13 fissures in 50 grains) compared to Mbam (5 fissures in 50 grains) and Lagdo (4 fissures in 50 grains) hubs ( $\mathrm{F}=27$, $\mathrm{P}=0.001$ ) (Figure 5(b)). Fissures in rice grains may be caused by moisture re-absorption by dry paddy, moisture re-absorption by field paddy grains or by rapid drying of paddy [33]. In areas with high thermal amplitudes, such fissures are expected to be high as is the case in Ndop hub. During the early ripening process, the grain loses moisture only. Later, the grain dries during the day and then may re-absorb some moisture at night before continuing the drying process on the following day. When a rice grain dries to below $14 \%$ or $15 \%$ moisture content during the day and then re-absorbs moisture at night, the grain usually fissures due to moisture re-absorption [33]. This will be severe if the difference in the minimum and maximum daily temperatures is very high. This was the case with Ndop hub where thermal amplitudes and the differences between the minimum and maximum daily temperatures were higher compared to Mbam and Lagdo hubs. In addition, the increase in the annual mean temperature in Ndop hub above $1^{\circ} \mathrm{C}$ over a longer period of time (9 years, between 1990 and 2002) confirms that the hub is experiencing higher temperatures compared to previous years. Although mean temperatures are higher in Lagdo hub than in Ndop hub, increase in the mean annual temperature in Lagdo was only in 5 years between 1990 and 2002. Poor threshing methods in SSA countries, whereby the panicle is hit on a sick, stone or drum to release the rice grain may also cause fissures in such grains. The three RDHs where samples were collected, used similar threshing methods, thus the difference observed in the number of fissures could be attributed to moisture re-absorption by dry paddy, moisture re-absorption by field paddy grains or by rapid drying of paddy in the field which was made worse by high thermal amplitudes and temperature variations especially in Ndop hub.

\subsubsection{Broken Fractions in Rice}

Rice produced in Cameroon generally has high levels of broken fraction (35\% - 63\%). In this study, rice was milled using three different types of mills. The highest proportion of broken fractions as expected was recorded with the Engelberg type mills (50\% - 63\%), followed by the Satake Commercial rubber roll type mills (36\% $46 \%)$ and the least with the Satake laboratory hand de-husker (11\% - 17\%) (Figure 6(a)). Rice produced in the Mbam hub and milled with there had the highest proportion of broken fraction (54\% - 63\%) followed by Lagdo (43\% - 52\%) and the least recorded in Ndop (35\% - 38\%) (Figure 6(b)). These results suggest that the main rea- 


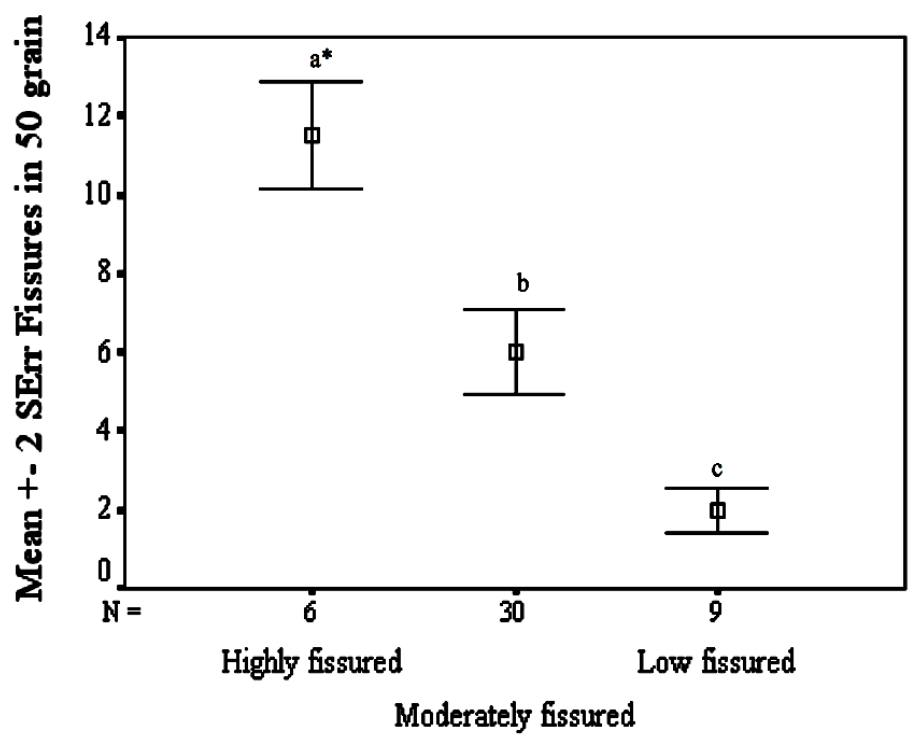

Varietal Class for fissures in grains

$\begin{array}{lll}\text { Highly fissured } & \text { Moderately fissured } & \text { Low fissured } \\ \text { - IR46 } & \text {-ITA300 } & \text {-Tianan-5 } \\ \text { - Madam } & \text {-NERICA-3 } & - \text { Tox3145 } \\ & \text {-NERICA-8 } & - \text { M13 } \\ & \text {-CICA-8 } & \\ \text {-NERICA-L42 } & \end{array}$

(a)

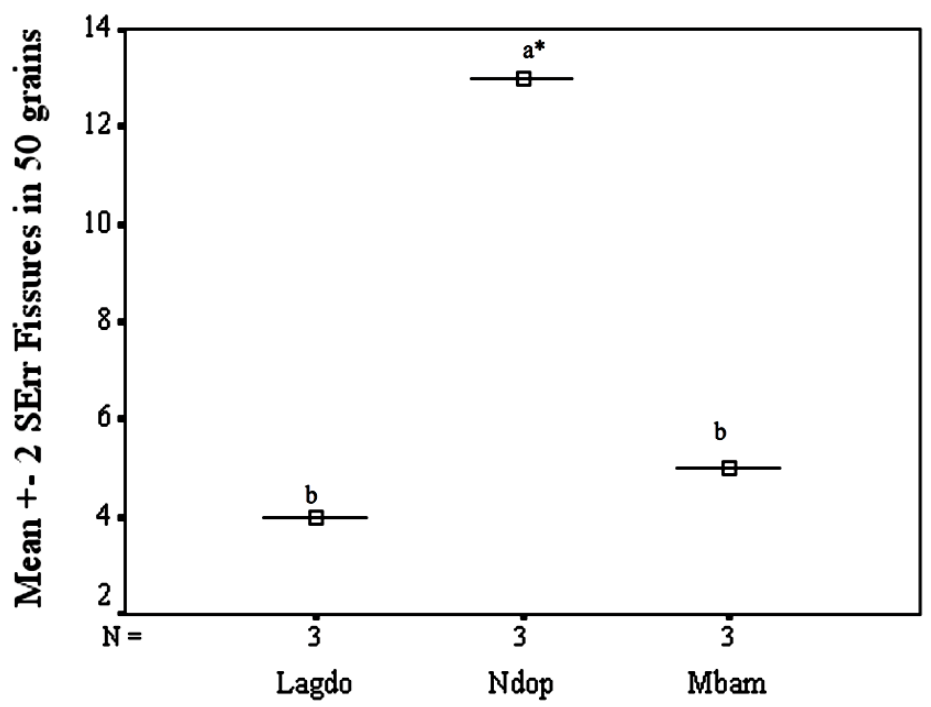

\section{Rice Development Hub}

(b)

Figure 5. (a) Classification of major rice varieties produced in Cameroon into three classes based on number of fissures in 50 grains using a pooled rice sample milled using rice mills located in three rice development hubs (Ndop, Mbam and Lagdo) of Cameroon. "Bars with different letters signify significant difference at 0.05 level; (b) Number of fissures in 50 grains recorded from NERICA-3 rice collected from different rice development hubs in Cameroon and milled using a laboratory hand de-husker. ${ }^{*}$ Bars with different letters signify significant difference at 0.05 level. 


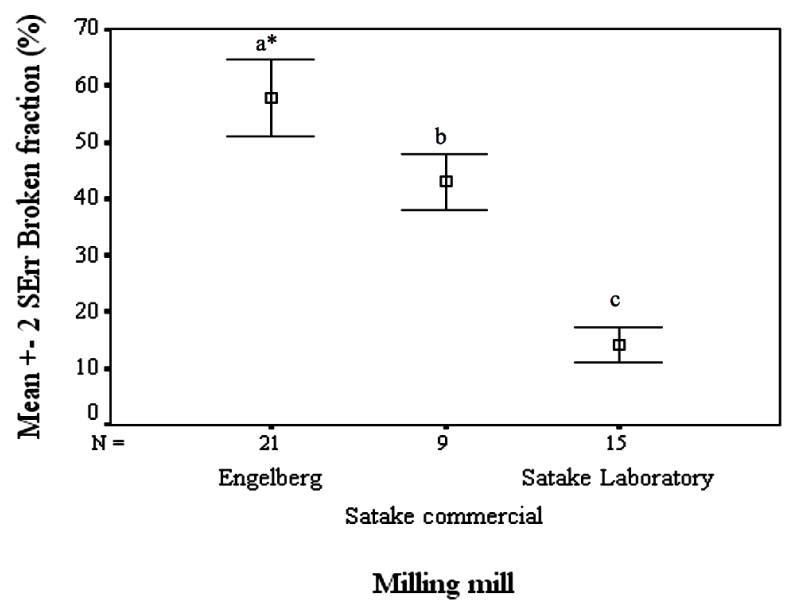

(a)

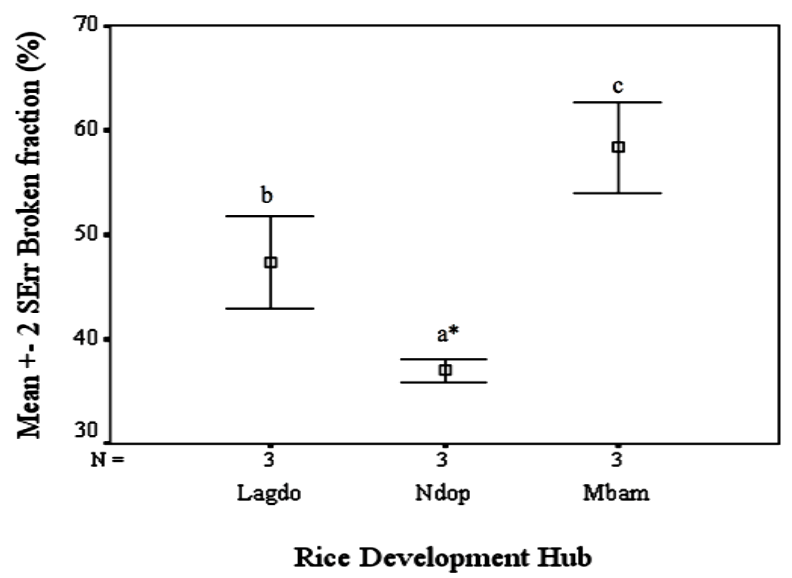

(b)

Figure 6. (a) The rate of broken fraction recorded for rice milled using different types of mills found in Cameroon; (b) The rate of NERICA-3 broken rice fractions recorded from samples milled using the mills present in the different rice development hubs of Cameroon. *Bars with different letters signify significant difference at 0.05 level.

son for the relatively high proportion of broken fractions in Mbam and Lagdo compared to Ndop was the types of mills used in these hubs. In Mbam hub, only the Engelberg type mills that produced very high proportion of broken fractions are available. On the other hand, in Lagdo hub, Engelberg and rubber roll mills are present while in Ndop only rubber roll mills, which produced relatively lower levels of broken fractions were present.

The milled rice obtained from different rice varieties in this study was grouped into three distinct classes (Highly broken, moderately broken and low broken) based on the\% broken fractions $(\mathrm{F}=120, \mathrm{P}=0.0001)$. One variety-IR46-was highly broken (75\% - 80\%), 3 varieties-ITA-300, TOX-3145, CICA-8-were moderately broken (55\% - 70\%) while 6 varieties-Tainan-5, NERICA-3, M-13, Madam, NERICA-8 and NERICA-L42had low broken fractions (23-30\%) (Figure 7(a)). When paddy samples of NERICA-3 from the hubs were milled using a Satake laboratory hand de-husker, samples from Ndop hub recorded comparably higher proportion of brokens (21\% - 36\%) compared to Lagdo and Mbam hubs (9\% - 18\%) (Figure 7(b)). This confirmed that the type of mills used in Mbam and Lagdo hubs were primarily responsible for the breakage levels in milled rice while for Ndop hub, the most important factor was temperature variations and the quality of the paddy. The pattern observed for the proportion of broken fraction was similar to that observed for fissures in grains suggesting that the factors that caused high number of fissures recorded in Ndop hub compared to Lagdo and Mbam hubs were responsible for the high proportion of broken fractions in Ndop hub with NERICA-3. A strong correlation 


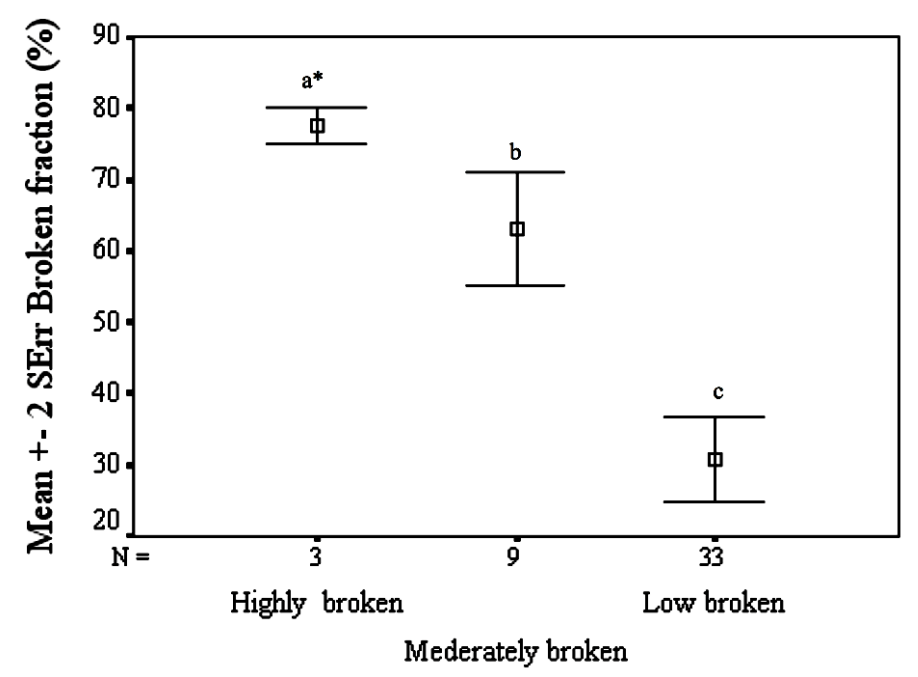

\section{Varietal Class for broken fractions}

$\begin{array}{lll}\text { Highly broken } & \text { Moderately broken } & \text { Low broken } \\ - \text { IR46 } & - \text { ITA300 } & \text {-Tianan-5 } \\ & - \text { Tox3145 } & \text { - NERICA-3 } \\ \text { - CICA-8 } & - \text { M13 } \\ & - \text { Madam } \\ & - \text { NERICA-8 } \\ & - \text { NERICA-L42 }\end{array}$

(a)

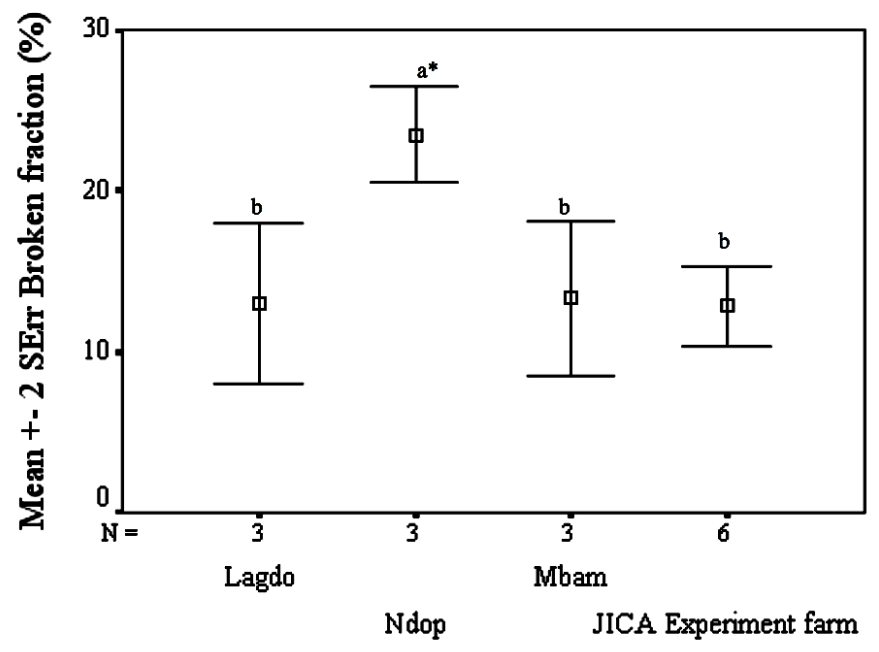

\section{Rice Development Hub}

(b)

Figure 7. (a) Classification of major rice varieties produced in Cameroon into three classes based on broken rice fraction using a pooled sample from three rice development hubs (Ndop, Mbam and Lagdo) of Cameroon. * Bars with different letters signify significant difference at 0.05 level; (b) Rate of broken rice fraction of NERICA-3 collected from different rice development hubs in Cameroon and from the Japan International Cooperation Agency (JICA) rice project site in Nkolbisson, Yaounde-Cameroon and milled using a laboratory hand de-husker. 
was also observed between thermal amplitudes and the proportion of broken fractions $(\mathrm{R}=0.80, \mathrm{P}<0.05)$ using milled samples from the laboratory hand de-husker.

\subsection{Postharvest Adaptation Strategies}

\subsubsection{Improved Parboiling Technology}

When the paddy of TOX-3145 rice was parboiled using the improved (uniform steam-distributed, USD) parboiling technology [20], the \% chalky grains, fissures in 50 grains and \% broken fractions were reduced $(\mathrm{P}<$ 0.05) compared to when the rice was not parboiled or parboiled using the traditional technology (Table 2). The complete elimination of chalkiness in samples parboiled using the USD parboiling technology confirm the finding of [11] who observed that rice grains, which are rather opaque, become somewhat glassy and translucent upon proper parboiling. This was probably due to adhesion of gelatinized starch granules and disrupted protein bodies during parboiling to form a compact mass reducing light scattering at the boundaries of the granules. Reduction in the number of fissures and broken fractions in USD parboiled rice confirms that after rice is properly parboiled in this process and subsequently air-dried in the sun to a moisture of $18 \%$ followed by shade drying to a moisture of $14 \%$, grain breakage during milling is close to zero irrespective of its level of fissures before parboiling [12]. Improved parboiling can thus be used in SSA countries as an adaptation strategy to mitigate the effect of changing climatic conditions and poor postharvest handling practices on grain quality of locally produced rice.

\subsubsection{Recovery of Poorly Filled and Immature Grains}

It is common practice in the rice parboiling industry to discard immature and poorly filled grains during parboiling. In SSA countries, this is done by submerging paddy rice in water and allowing the immature and poorly filled grains to float and subsequently discarded. High temperatures during the ripening stage of rice may cause immature and poorly filled grains [3]. In this study, these immature and poorly filled grains were collected, cleaned, parboiled, dried and milled separately. Through this process, about $4.2 \%$ of milled rice that should have normally been lost was recovered. This rice, although of poor physical quality, could be used to feed livestock or processed into other products.

\subsubsection{Value-Addition to Low-Grade and Fine Broken Rice Fractions via Processing into Biscuits}

In Cameroon, low-grade and fine broken rice is used in the Northern part of the country for the production of a local meal "Gniri". Gniri is made by cooking low-grade or fine broken rice in water and mashing it to produce a paste that is eaten with a local sauce. In addition some local processors use it for the making of rice porridges and rice "doughnuts" after grinding into flour. However, these practices are not common in the Southern part of the country and as such low-grade and fine broken rice is sold very cheaply as a feed for livestock. In this study, fine broken rice (100\% broken) was used to produce rice biscuits. The biscuits were highly accepted by a test panel at IRAD confirming earlier results by [24]. In addition, the proportion of those who liked the color, taste and texture of rice biscuits was not different using the chi-square $(\chi)$ test $\left(\chi^{2}=0.09\right.$, $\mathrm{df}=1, \mathrm{~N}=36$ ) from that of wheat biscuits. Forty-five (45) percent of the panelist could not correctly say which flour type (wheat or rice) was used for making the biscuits.

\section{Conclusions}

In this study, the level of chalky white rice, fissures in rice grains and broken rice fractions in three contrasting RDHs (Lagdo, Ndop and Mbam) in Cameroon were evaluated. The mean \% chalky grains from all RDHs in

Table 2. Effect of parboiling on some physical quality parameters of TOX3145 rice variety produced in Cameroon.

\begin{tabular}{cccc}
\hline Quality Attribute & WNP & IP & TP \\
\hline Broken fraction (\%) & $66.11( \pm 1.4)$ & $5.35( \pm 2.0)^{*}$ & $44.95( \pm 1.0)$ \\
Fissures in 50 grains & $6.00( \pm 1.4)$ & $1.00( \pm 0.4)^{*}$ & $11.00( \pm 1.7)$ \\
Chalky grains (\%) & $35.0( \pm 1.3)$ & $1.02( \pm 0.01)^{*}$ & $4.56( \pm 0.4)$ \\
\hline
\end{tabular}

WNP = White nonparboiled rice, IP = Improved parboiled rice, TP = Traditional parboiled rice. ${ }^{*}$ Means are significantly different at 0.05 level. 
Cameroon was more than $20 \%$ and a score of 9 was attributed to these samples according to [28]. Environmental conditions in Ndop hub may favor the development of chalkiness in rice varieties grown in that hub especially those varieties with a genetic predisposition to chalkiness. A positive correlation was observed between thermal amplitudes, fissure in grains and \% broken fractions in milled rice.

Thermal amplitudes and the differences between the daily minimum and maximum temperatures were the highest in Ndop hub compared to Mbam and Lagdo. Milled rice produced in Cameroon generally has a high proportion of broken fractions. However, the main factors responsible depend on the hub where the rice is produced. In Mbam and Lagdo, the main factor causing grain breakage is the type of mills used for de-husking and polishing. In Ndop, the main factors responsible are high thermal amplitudes and temperature variations especially during the rice ripening stage. This does not, however, rule out the contribution of other factors such as poor harvesting, threshing and drying methods that are common in all the RDHs. An improved parboiling technology, the recovery and processing of poorly filled and immature grains and the processing of rice with a high proportion of broken fractions into biscuits or other products generally accepted by the local population can be implemented as adaptation strategies to the effects of temperature variations and poor postharvest operations on physical quality of the rice grain especially in SSA countries. These strategies will increase the revenue of rice value-chin actors by reducing quantitative and qualitative postharvest losses.

\section{Acknowledgements}

This work received financial assistance from the Canadian International Development Agency (CIDA) sponsored project on "Enhancing food security in Africa through the improvement of rice postharvest handling, marketing and the development of new rice-based products”.

\section{References}

[1] Morton, J.F. (2007) The Impact of Climate Change on Smallholder and Subsistence Agriculture. Proceedings of the National Academy of Sciences, 104, 19680-19685. http://dx.doi.org/10.1073/pnas.0701855104

[2] Howden, S.M., Soussana, J.-F., Tubiello, F.N., Chhetri, N., Dunlop, M. and Meinke, H. (2007) Adapting Agriculture to Climate Change. Proceedings of the National Academy of Sciences, 104, 19691-19696. http://dx.doi.org/10.1073/pnas.0701890104

[3] Wassmann, R., Jagadish, S.V.K., Heuer, S., Ismail, A., Redona, E., Serraj, R., Singh, R.K., Howell, G., Pathak, H. and Sumfleth, K. (2009) Climate Change Affecting Rice Production: The Physiological and Agronomic Basis for Possible Adaptation Strategies. Advances in Agronomy, 101, 59-122. http://dx.doi.org/10.1016/S0065-2113(08)00802-X

[4] Barnabas, B., Jager, K. and Feher, A. (2008) The Effect of Drought and Heat Stress on Reproductive Processes in Cereals. Plant Cell Environment, 31, 11-38. http://dx.doi.org/10.1111/j.1365-3040.2007.01727.x

[5] Osada, A., Sasiprada, V., Rahong, M., Dhammanuvong, S. and Chakrabandhu, M. (1973) Abnormal Occurrence of Empty Grains of Indica Rice Plants in the Dry, Hot Season in Thailand. Proceeding of the Crop Science Society of Japan, 42, 103-109.

[6] Yoshida, S. and Hara, T. (1977) Effects of Air Temperature and Light on Grain Filling of an Indica and a Japonica Rice (Oryza sativa L.) under Controlled Environmental Conditions. Soil Science and Plant Nutrition, 23, 93-107. http://dx.doi.org/10.1080/00380768.1977.10433026

[7] Zhang, Z., Zhang, S., Yang, J. and Zhang, J. (2008) Yield, Grain Quality and Water Use Efficiency of Rice under Non-Flooded Mulching Cultivation. Field Crops Research, 108, 71-81. http://dx.doi.org/10.1016/j.fcr.2008.03.004

[8] Leeper, J. (2011) A Consumer’s Guide to Rice. Rice Today, 10, 38-39.

[9] Rao, R.S.N. and Juliano, B.O. (1970) Effect of Parboiling on Some Physicochemical Properties of Rice. Journal of Agricultural and Food Chemistry, 18, 289-294. http://dx.doi.org/10.1016/j.fcr.2008.03.004

[10] Ali, N. and Ojha, T.P. (1976) Parboiling. In: Araullo, E.V., de Padua, D.B. and Graham, M., Eds., Rice Postharvest Technology, International Development Research Center, Ottawa, 163-204.

[11] Bhattacharya, K.R. (1985) Parboiling of Rice. In: Juliano, B.O., Ed., Rice Chemistry and Technology, American Association of Cereal Chemists, Inc., Minnesota, 289-348.

[12] Bhattacharya, K.R. (1980) Breakage of Rice during Milling: A Review. Tropical Science, 22, 255-276

[13] Diop, A., Hounhouigan, D. and Kossou, K.D. (1997) Manuel de Référence pour Technicien Spécialisés: Technologie Post-récolte et Commercialisation des Produits Vivriers. ADA Experts-Conseils, Québec, 89-109.

[14] Behrens, J.H. and Heinemann, R.J.B. (2007) Parboiled Rice, a Study about Attitude, Consumer Liking and Consump- 
tion in Sao Paul, Brazil. Journal of Science and Food Agriculture, 87, 992-999. http://dx.doi.org/10.1002/jsfa.2794

[15] Ndindeng, S.A. (2012) Report on the Selection of Rice Development Hubs for Cameroon. IRAD, Yaoundé, 1-18.

[16] AfricaRice (2011) Boosting Africa’s Rice Sector: A Research for Development Strategy 2011-2020. AfricaRice, Cotonou, ii+77.

[17] Ruiten, H.T.L. (1985) Rice Milling: An Overview. In: Juliano, B.O., Ed., Rice Chemistry and Technology, American Association of Cereal Chemists, Inc., Minnesota, 349-388.

[18] Lisle, A.J., Martin, M. and Fitzgerald, M.A. (2000) Chalky and Translucent Rice Grains Differ in Starch Composition and Structure and Cooking Properties. Cereal Chemistry, 77, 627-632.

[19] Courtois, F., Faessel, M. and Bonazzi, C. (2010) Assessing Breakage and Cracks of Parboiled Rice Kernels by Image Analysis Techniques. Food Control, 2, 567-572.

[20] Ndindeng, S.A., Manful, J.T., Futakuchi, K., Mapiemfu, L.D., Bigoga, J., Tang, E.N., Akoa-Etoa, J.M., Ngome, A.F andMoreira, J. Development of an Improved Parboiling Technology for Small to Medium-Scale Rice Processors in Sub-Saharan Africa. Journal of Food Science and Technology, under Review.

[21] Akoa Etoa, J.M., Ndindeng, S.A., Owusu, E.S., Woin, N., Bindzi, B. and Demont, M. Reversing Urban Bias through Improved Rice Parboiling: Experimental Evidence from Cameroon. Quarterly Journal of International Agriculture, under Review.

[22] Fofana, M., Wanvoeke, J., Manful, J.T., Futakuchi, K., Van Mele, P., Zossou, E. and Bléoussi, T.M.R. (2011) Effect of Improved Parboiling Methods on the Physical and Cooked Grain Characteristics of Rice Varieties in Benin” International Food Research Journal, 18, 697-703.

[23] Koutroubasa, S.D., Mazzinib, F., Ponsc, B. and Ntanosd, D.A. (2004) Grain Quality Variation and Relationships with Morpho-Physiological Traits in Rice (Oryza sativa L.) Genetic Resources in Europe. Field Crops Research, 86, 115130. http://dx.doi.org/10.1016/S0378-4290(03)00117-5

[24] Ndindeng, S.A., Ambang, Z., Woin, N., Ngome, A.F., Njebu, S.A., Mapiemfu, D.L., Leke, W.N., Akoa-Etoa, J.M., Chi, G.L. and Mbah, V.T. (2012) Valorization of Dacryodes edulis Fruit (Safou) through Improved Drying Procedures, Packaging and Processing. Frontiers in Science, 2, 250-255. http://dx.doi.org/10.5923/j.fs.20120206.19

[25] Krishnan, P., Ramakrishnan, B., Reddy, K.R. and Reddy, V. (2011) High Temperature Effects on Rice Growth, Yield, and Grain Quality. Advances in Agronomy, 111, 87-205. http://dx.doi.org/10.1016/B978-0-12-387689-8.00004-7

[26] Wimberly, J.E. (1983) Technical Handbook for the Paddy Postharvest Industry in Developing Countries. International Rice Research Institute, Los Banos, 1-188.

[27] Calderwood, D.L., Cogburn, R.R., Webb, B.D. and Marchetti, M.A. (1984) Aeration of Rough Rice in Long-Term Storage. Transaction of the American Society of Agricultural Engineering, 27, 1579-1585. http://dx.doi.org/10.13031/2013.33007

[28] International Rice Research Institute (2009) Procedures for Measuring Quality of Milled Rice. Rice Knowledge Bank, IRRI, Los Baños. http://www.knowledgebank.irri.org

[29] Tan, Y.F., Xing, Y.Z., Li, J.X., Yu, S.B., Xu, C.G. and Zhang, Q.F. (2000) Genetic Bases of Appearance Quality of Rice Grains in Shanyou 63, an Elite Rice Hybrid. Theoretical and Applied Genetics, 101, 823-829. http://dx.doi.org/10.1007/s001220051549

[30] Li, J.M., Xiao, J.H., Grandillo, S., Jiang, L.Y., Wan, Y.Z., Deng, Q.Y., Yuan, L.P. and McCouch, S.R. (2004) QTL Detection for Rice Grain Quality Traits Using an Interspecific Backcross Population Derived from Cultivated Asian (Oryza. sativa L.) and African (Oryza. glaberrima S.) Rice. Genome, 47, 697-704. http://dx.doi.org/10.1139/g04-029

[31] Yamakawa, H., Hirose, T., Kuroda, M. and Yamaguchi, T. (2007) Comprehensive Expression Profiling of Rice Grain Filling-Related Genes under High temperature Using DNA Microarray. Plant Physiology, 144, 258-277. http://dx.doi.org/10.1104/pp.107.098665

[32] Zhou, L., Chen, L., Jiang, L., Zhang, W., Liu, L., Liu, X., Zhao, Z., Liu, S., Zhang, L., Wang, J. and Wan, J. (2009) Fine Mapping of the Grain Chalkiness QTL qPGWC-7 in Rice (Oryza sativa L.). Theoretical and Applied Genetics, 118, 581-590. http://dx.doi.org/10.1007/s00122-008-0922-0

[33] Kunze, O. (2008) Effect of Drying on Grain Quality—Moisture Reabsorption Causes Fissured Rice Grains. The CIGR Ejournal, Agricultural Engineering Institute, 1-17. http://www.cigrjournal.org/index.php/Ejounral/article/viewFile/1333/1163 
Scientific Research Publishing (SCIRP) is one of the largest Open Access journal publishers. It is currently publishing more than 200 open access, online, peer-reviewed journals covering a wide range of academic disciplines. SCIRP serves the worldwide academic communities and contributes to the progress and application of science with its publication.

Other selected journals from SCIRP are listed as below. Submit your manuscript to us via either submit@scirp.org or Online Submission Portal.
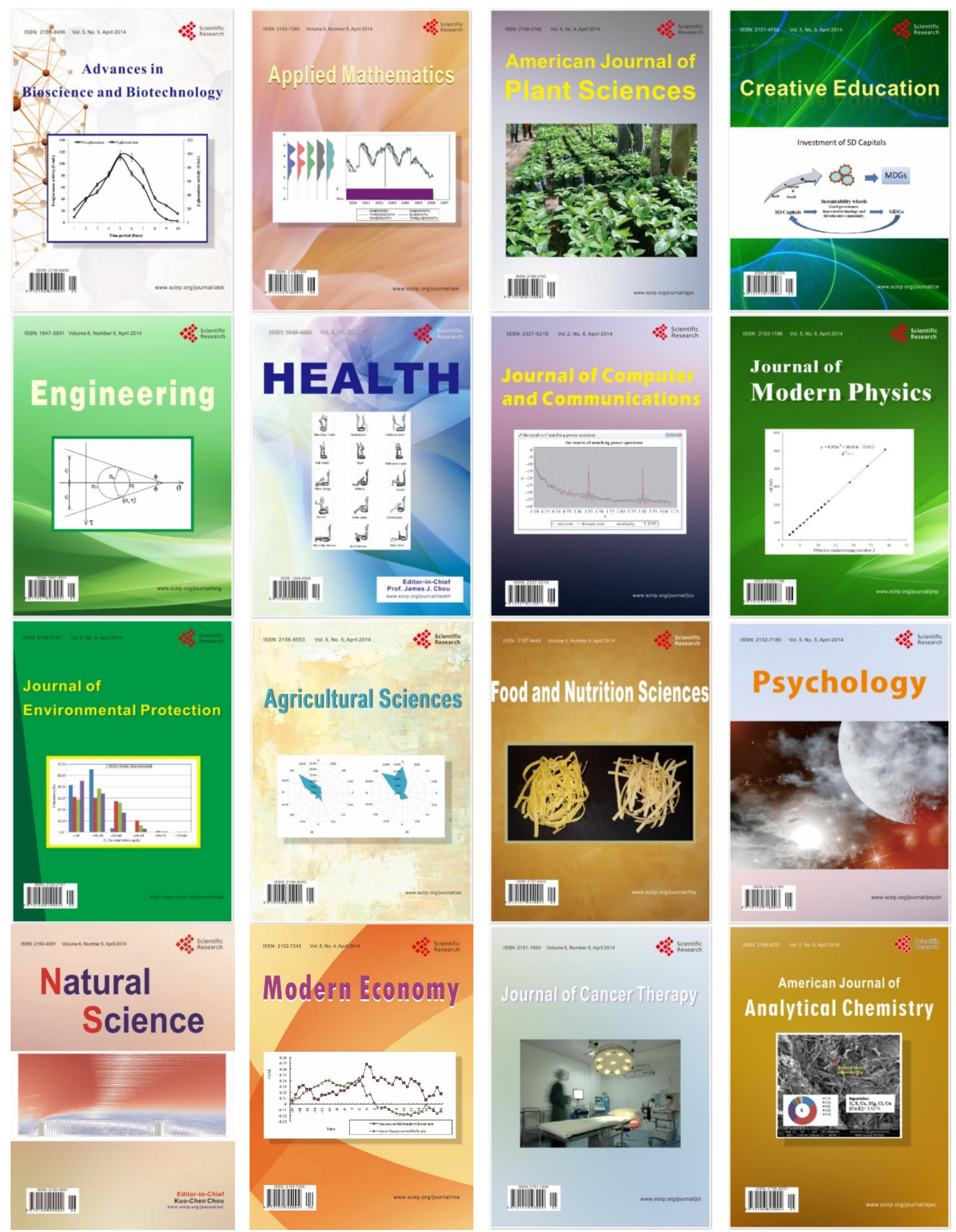